\title{
Sentidos de la Potencialidad Crítica, Política y TRansformadora DE LAS ARTES
}

\author{
Julieta Infantino \\ Universidad de Buenos Aires, Argentina ${ }^{1}$
}

\begin{abstract}
En las últimas décadas artistas, trabajadores culturales, educadores, diseñadores de politicas públicas e intelectuales, entre otros, vienen desplegando una variedad de propuestas que promueven la transformación social desde los más diversos lenguajes artísticos. Orquestas infanto-juveniles, teatros comunitarios, circos sociales, grupos de danza o de artistas visuales y demás experiencias que parten de distintos lenguajes artísticos, los conjugan, colectivizan, territorializan y proponen intervenir en nuestras desiguales sociedades latinoamericanas disputando una resignificación del rol social y politico del arte en tanto herramientalestrategia de intervención social y disputa politica por la ampliación de derechos. En este trabajo propongo sistematizar algunas lineas de reflexión en relación a los usos sociales y politicos del arte para recorrer procesos históricos, tensiones y disputas que evidencian como los sentidos con los que se connota el potencial transformador, crítico/politico del arte no son univocos y emergen de coyunturas diferenciales asi como de intereses y contextos politico-ideológicos específicos.

Palabras clave: arte, transformación social, políticas culturales
\end{abstract}

\section{INTRODUCCIÓN}

Tal como analicé en distintos trabajos (Infantino, 2016, 2018a, 2019b), desde mediados de los años 1990, aunque con mayor intensidad en los 2000, los usos del arte para la transformación/inclusión/intervención social comienzan a ocupar cada vez más espacios en Latinoamérica

\footnotetext{
1 Investigadora Adjunta CONICET (Consejo Nacional de Investigaciones Científicas y Tecnológicas). Instituto de Ciencias Antropológicas, Facultad de Filosofía y Letras, Universidad de Buenos Aires, Argentina. E-mail: julietainfantino@gmail.com
} 
y, específicamente en Argentina, ámbito en el que centro mi investigación individual y colectiva que recupero en este trabajo. ${ }^{2}$

Los vínculos entre el arte y su potencial social y político no son nuevos, y podríamos rastrear sus antecedentes a diferentes movimientos vanguardistas/críticos que en distintos contextos abogaron por que el arte sea una herramienta política, de emancipación, de crítica, de disputa ante inequidades sociales, entre otros aspectos. Pero es en el contexto de los años 19902000 cuando estos usos comienzan a adquirir algunos sentidos específicos. Así, desde propuestas comunitarias, independientes/autogestivas, públicas y/o de gestión mixta se implementan acciones y políticas (culturales, pero también, educativas, sociales, de salud, trabajo), enfocadas hacia sectores vulnerabilizados afectados por procesos de inequidad, pobreza, desigualdad en el terreno de la cultura y en otras áreas de la vida económica y social. Este tipo de propuestas artísticas, pedagógicas y de intervención social parten desde los más variados lenguajes: música, circo, danza, artes visuales, fotografía, comunicación, teatro comunitario, entre otros.

Sostengo que el crecimiento de estas propuestas arte-transformadoras en Argentina se vincula con un proceso del que podemos destacar algunas aristas que se entrelazan: a) ampliación/pluralización del concepto de cultura y política cultural; b) instrumentalización de las artes y la cultura; c) resignificación de las potencialidades políticas del arte.

a) Desde los años 1980, el concepto de política cultural dejó de ser tomado en su sentido restringido, como un instrumento para ofrecer servicios y acceso a "la cultura", en conjunción con la ampliación de esta noción que comienza a ser apelada desde un "sentido antropológico" trascendiendo su restricción a las bellas artes o el patrimonio (García Canclini, 1987; Bayardo, 2008; Vich, 2014; Crespo, et. Al., 2015). A partir de aquí, las políticas culturales pasaron a acentuar su carácter plural, como herramienta con múltiples fines y en la que intervienen una diversidad de agentes. Organismos internacionales, agencias estatales, movimientos sociales, organizaciones civiles, grupos comunitarios y artistas apelan desde distintos sentidos y desiguales condiciones de poder al arte y a la cultura. Cultura que, como señala Yúdice, se convirtió en un "recurso" para una diversidad de propósitos que trascienden lo simbólico y se intersectan con lo político, lo social y lo económico (Yúdice, 2002).

b) La conversión de las políticas culturales en políticas económicas primero -procesos de regeneración/recualificación urbana o espectacularización/mercantilización de la cultura y el patrimonio- y luego en políticas sociales -arte para la inclusión/desarrollo/transformación social- provocó cierta presión sobre los mundos de arte por justificar sus acciones artísticas primero como medios para lograr desarrollo y rentabilidad económica y luego en términos de impacto/utilidad social (Belfiore, 2002; Infantino, 2019b). ${ }^{3}$ En Argentina, estos procesos implicaron

2 Comparto en este artículo una sistematización de algunos de los resultados de una investigación individual que estoy desplegando en mi trayecto postdoctoral centrada en los usos sociales y políticos del arte (circense) en conjunción con debates y reflexiones que venimos desarrollando desde el equipo de investigación que coordino: Equipo de Investigación en Artes, política(s) y transformación social. Desde allí propusimos trabajar casos etnográficos diversos que incorporan el uso de las artes para la transformación social desde distintos lenguajes -teatro comunitario, orquestas infantiles y juveniles, danza, circo, fotografía-. Para profundizar en los resultados mencionados ver: Infantino, 2019a.

3 Si bien el foco de este trabajo estará centrado en Argentina, cabe aquí destacar que los procesos que reseño se desarrollan en distintas geografías, en algunos casos de modos similares y en otros con temporalidades y acentos diferenciales. Por ejemplo, los procesos globales de ponderación de la cultura como estrategia para el desarrollo (económico y social), si bien presentes desde los años 80, se plasman con intensidad en el país en la década si- 
especificidades, centralmente vinculadas al retiro del Estado como garante de derechos y a la reducción del gasto público en los años 1990 de auge de políticas de corte neoliberales. Aquí "la cultura" y las "artes" no solo fueron valoradas en términos "rentables", sino que se asistió a una justificación instrumental del recurso de la cultura en función de aportar soluciones a problemáticas económicas y sociales. La cultura se presentó entonces como "la solución" para enfrentar los efectos del neoliberalismo, ya sea desde un discurso de inclusión, asistencia, prevención y/o control de las poblaciones vulneradas como desde los beneficios económicos que la creatividad, la cultura y el arte traerían aparejados para las cada vez más desiguales ciudades del país.

c) En este contexto, las búsquedas por transformar nuestra sociedad desde el arte implicaron ciertas resignificaciones pero también actualizaciones de nociones como arte político, comprometido, crítico. Desde el cuestionamiento frente al reduccionismo de la politicidad del arte al contenido/temática/mensaje de la obra al desafío frente a las jerarquías culturales hegemónicas y las reglas de juego del campo artístico se fue arribando a la idea de la obra de arte y la práctica artística como herramienta para la transformación social, intersectando el campo artístico con otros campos -social, económico, político- (García Canclini, 2010; Richard, 2011). Si bien la instrumentalización del arte y la cultura conllevó el despliegue de acciones frecuentemente entrampadas en su uso instrumental, también muchos artistas cuestionaron con mayor o menor éxito la potencialidad político-crítica del arte en tanto herramienta para imaginar alternativas más democráticas e igualitarias en las que la cultura y el arte se erigen y disputan como derecho.

Muchas de las propuestas arte-transformadoras que en Argentina surgen y/o se afianzan en el contexto de época que recorrí, se vieron influenciadas por los discursos que instalaron la instrumentalización de la cultura y las artes para el desarrollo económico y la inclusión -asistencia/gestión/control- de los sectores desfavorecidos. Pero también estuvieron inmersas en los debates del campo artístico en relación a las diversas modalidades para repensar la potencialidad crítico-política de las artes. Por consiguiente, de modos complejos y no sin conflictos muchos de sus hacedores fueron luchando por sostener otras formas de pensar propuestas socio-artísticas que disputen su mera instrumentalización al calor también de recientes procesos de politización de la cultura (Wright, 2004).

La mirada antropológica y el enfoque etnográfico me fueron llevando a analizar estos sentidos disputados que tensionan las prácticas arte-transformadoras. Desde el inicio de mi trayectoria de investigación me interesó analizar las dinámicas desde las cuales se practican, se apropian/resignifican y se usan las artes. En este sentido, parto de la noción de que los conceptos nunca se presentan como unívocos en sus acepciones, sino más bien circulan, se usan (Menéndez, 2010) y se apropian con diferentes significados y desde diversos posicionamientos político-ideológicos de acuerdo a quién tiene el poder para definirlos y con qué fines (Wright, 2004). Arte y transformación social, pero también inclusión, derechos/políticas culturales, intervención, sectores vulnerables, creatividad, empoderamiento, potencialidad crítico-política del arte, son conceptos que desde la antropología podrían considerarse como categorías nativas, conceptos que se usan, con los que los agentes sociales con quienes trabajamos definen y redefinen sus prácticas. Conceptos que tienen sus historias, sus trayectorias y que circulan y son

guiente. O bien, las propuestas de recualificación urbana a través del arte desarrolladas en Europa al menos desde los años 1980, en Argentina toman fuerza como "estrategia de desarrollo" recién a partir de los años 90. Por consiguiente, si bien la argumentación en este texto se construyó dirigiendo la mirada hacia Argentina, esta se encuentra en articulación y diálogo con procesos globales y regionales. 
apropiados por actores sociales diversos que les otorgan sentidos diferenciales, en casos ideológicamente contrapuestos, y conforman entramados de negociaciones y disputas.

Decía que desde los inicios de mi investigación me interesó acercarme a los usos de las artes, específicamente a los modos en que jóvenes artistas circenses en Buenos Aires se acercaban a este lenguaje milenario, lo resignificaban y actualizaban. Encontré en estos procesos intersticios interesantes para estudiar los sentidos diversos que esos "usos del arte" conllevan, en tanto espacio de resignificación estética/estilística, como herramienta de disputa política por reconocimiento, en tanto ámbito para pelear por alternativas de vida y de trabajo o como instrumento de intervención social para luchar por la transformación de diversas injusticias que atraviesan a nuestras desiguales sociedades. Así, en los últimos años he acompañado a artistas circenses pero también, desde una investigación colectiva (Infantino, 2019a), a grupos que trabajan con diversos lenguajes artísticos enmarcados en propuestas de arte y transformación social. Investigué entonces tanto con técnicas ordinarias en el trabajo de campo antropológico- entrevistas en profundidad, observación participante- como con algunas experiencias de trabajo colaborativo. ${ }^{4}$ Estas implicaron, por ejemplo, la organización/coordinación en conjunto con los artistas de foros de debate en torno a las potencialidades transformadoras de las artes o en función de repensar condiciones de enseñanza, producción, gestión y trabajo artístico. Estas instancias de reflexión colectiva se convirtieron en un interesante insumo para estudiar las tensiones que atraviesan a este tipo de prácticas artísticas y para evidenciar los modos complejos en los que artistas, educadores y trabajadores culturales disputan sentidos críticos y democratizadores en estos ámbitos. Desde este recorrido, propongo en este trabajo sistematizar algunas líneas de reflexión en relación a los "usos sociales y políticos del arte" como conceptualización para evidenciar tanto procesos históricos como tensiones y disputas que se dan en torno a qué se comprende por potencial político-crítico-transformador del arte.

\section{LA TRANSFORMACIÓN ES POLÍTICA: RESIGNIFICACIONES DE LAS POTENCIALIDADES CRÍTICO-POLÍTICAS EN LAS ARTES}

Propongo comenzar por realizar una sistematización/balance de los modos en los que la noción de potencialidad política-crítica del $\operatorname{arte}^{5}$ para la transformación social se fue resignificando en las últimas décadas en Argentina, centralmente a partir del final de la última dictadura militar (1976-1983). En primer lugar analizaré cómo algunos grupos artísticos -principalmente provenientes del teatro- comenzaron a cuestionar el reduccionismo contenidista del arte político pre dictatorial para pasar a la acción: centralmente ocupando el espacio público callejero con

4 Recorrí algunas reflexiones en relación al rol de los académicos y las potencialidades y dilemas del trabajo/investigación en colaboración a partir de la experiencia de trabajo colectivo junto a la asociación civil Circo Abierto, sus disputas por reconocimiento (material y simbólico) ante el Estado y por políticas culturales democráticas y participativas. Para profundizar ver: Infantino, 2018b.

5 De acuerdo con Mouffe (2014) el potencial político del arte, ya sea en su carácter transformador o reproductor, se explica por su capacidad para contribuir a perpetuar o alterar la hegemonía. Por consiguiente, no habría una distinción entre arte político y no político ya que "desde el punto de vista de la teoría de la hegemonía, las prácticas artísticas cumplen una función en el mantenimiento de un orden simbólico dado, o en su desafío, y es por esto que tienen necesariamente una dimensión política" (Mouffe, 2014: 98). En este sentido, más que hablar de arte político sugiere manejar el concepto de arte crítico atendiendo a las diversas maneras en que las prácticas artísticas pueden contribuir a alterar la hegemonía dominante. En este trabajo suelo usar potencialidades crítico-políticas-transformadoras del arte en este sentido. 
arte. Muchas de las propuestas arte-transformadoras contemporáneas tienen sus raíces en estas experiencias que cuestionaron las jerarquizaciones artísticas así como sus espacios de circulación y sus protagonistas legítimos. Sostengo entonces que desde estos antecedentes partieron algunos de los usos del arte para la transformación social que se extendieron en años subsiguientes.

a) Del mensaje a la acción: ocupar el espacio público y cuestionar jerarquías artísticas

Desde las vanguardias artísticas e intelectuales de principios del siglo XX a los movimientos vanguardistas de los años 60 y 70, ${ }^{6}$ el campo del arte se caracterizó por la interpelación a lo que Bourdieu denominó “ilusión de autonomía” (Bourdieu, 1995). Tal como desarrolló el autor, el campo artístico define su especificidad en torno a esta autoproclamada autonomía ante otros campos -político, económico- en función de reglas propias en torno a la legitimidad cultural. Si bien el autor destaca cuan relativa es dicha autonomía, la misma es eje vertebrador de la constitución del campo. Es esta ilusión la que puede verse cuestionada a partir de propuestas que buscaron la disolución de las fronteras que definían al "arte por el arte", promoviendo su vinculación con la vida cotidiana, con la política, con la realidad social (García Canclini, 2010).

Estos movimientos internacionales que cuestionaron las jerarquías culturales hegemónicas, las reglas de juego del campo artístico y sus normas de legitimación fueron propiciando una deriva hacia la idea de la obra de arte y la práctica artística como herramienta para el cambio social, para la participación, para la crítica, para la transformación y la acción política.

Estas formas de conceptualizar las artes se habían practicado en Argentina desde diversos lenguajes artísticos en los años 60 y 70. Por ejemplo, las experiencias primero del Instituto Torcuato Di Tella y luego del llamado Teatro militante ${ }^{7}$ resultan referencias indispensables para pensar estas derivas de las prácticas artísticas y sus vínculos con el cuestionamiento, la crítica y la política. Algunos investigadores también señalan como la experiencia de Tucumán $\mathrm{Arde}^{8}$ se convirtió en una referencia central, construida más tarde como mito (Longoni, 2014), para pensar la historia del arte político/activista en Argentina. No obstante, estas propuestas vanguardistas, críticas y/o experimentales se enfrentaron a la censura, la persecución y la prohi-

$6 \quad$ Por movimientos vanguardistas en el arte desde los años 1960 refiero a movimientos que se despliegan en diversas territorialidades. Desde propuestas contraculturales juveniles - hippies, bohemios- a experimentaciones estéticas que cuestionaban el modo de reproducción hegemónica del campo artístico -arte conceptual, arte relacional, arte activista, Happening, perfomance-. Para profundizar, ver García Canclini, 2010.

$7 \quad$ El Di Tella en los años 60 se convirtió en un espacio de experimentación vanguardista en el que se entrecruzaban distintos lenguajes artísticos como la música, el teatro, la danza o las artes visuales, experimentando desde el happening o la performance teatral y desplegando lo que Verzero (2013) caracteriza por "liminalidad disciplinaria". Ya para finales de los años 60 y principios de los 70, en un contexto de radicalización política y alta politización del campo artístico, algunos grupos del campo teatral se volcaron a desplegar propuestas de intervención teatral militante. Se trataba de prácticas experimentales y coyunturales, intervenciones espontáneas, semiclandestinas que buscaban la participación del público con algún fin político o social (Verzero, 2013; Mercado, 2018).

8 En 1968 un grupo de artistas que habían decidido alejarse del Di Tella, retoman como eje para su acción artístico política "la denuncia de la gravedad de la crisis que asolaba a buena parte de la población tucumana a causa del cierre de los ingenios azucareros" (Longoni, 2014: 3) y despliegan una serie de acciones divididas en etapas que se convirtieron en uno de los intentos más cabales "de formular un programa colectivo para continuar haciendo arte por fuera del arte” (Longoni, 2014: 4). Según Longoni, a pesar del mito construido desde el campo artístico, académico y activista, Tucumán Arde puede seguir siendo pensado desde su densidad crítica, como el mayor intento colectivo -y aquí reside un aspecto relevante de su potencia en torno a experimentar nuevas formas de hacer en común- de sostener la articulación entre experimentación artística y acción política con el fin de contribuir desde el arte experimental a la revolución. 
bición -sumado al exilio y/o desaparición de muchos de sus hacedores- durante los años de dictadura militar.

Una vez finalizado el proceso dictatorial aquellas conceptualizaciones y prácticas de un arte crítico, transgresor y libre ocuparon la escena argentina conjugando performances en espacios novedosos o "no convencionales" -galpones, centros culturales ${ }^{9}$ junto a actuaciones en los espacios públicos. Así, artistas de todos los colores y estilos invadieron el espacio callejero donde se entrecruzaban músicos/as, cirqueros/as, teatreros/as, murgueros/as, bailarines/as que ocupaban con arte las calles, parques, plazas y demás espacios públicos de la Ciudad de Buenos Aires y de distintas ciudades centrales de la Argentina como Córdoba, Rosario, Santa Fe, entre otras.

De esta manera, se iba instalando en el espacio público un arte que en cierta medida reelaboraba y modificaba algunas de las características que estas propuestas habían tenido en períodos previos a la dictadura. Una de estas reelaboraciones se vincula con la intencionalidad de trascender cierto reduccionismo en el arte comprometido/político pre-dictatorial vinculado con conceptualizaciones que depositaban en el arte una funcionalidad e instrumentalización con vías a lograr la emancipación/revolución. Tal como señala Nelly Richard, en la

retórica del arte comprometido, la ideología - contenido y representación — precede a la obra como el dato que ésta debe ilustrar: poner en imágenes. (...) 'el arte debe poner sus instrumentos al servicio de la sociedad para que el mensaje al alcance del pueblo tenga la mayor claridad revolucionaria'. Explicitud referencial y eficacia pedagógica son los criterios del didactismo revolucionario que le permitirá al artista sacudir la conciencia crítica de la sociedad, empujando el arte y la realidad hacia una utopía de cambio social pre-formulada desde la política. (Richard, 2011, s/p)

En el contexto post dictadura, el didactismo revolucionario comienza a perder su centralidad para entremezclarse con otras búsquedas políticas y artísticas que comenzaron a cuestionar la centralidad del "mensaje" en la obra artística como eje para medir su potencialidad crítica. Sin embargo, resulta interesante destacar que estas lecturas críticas de ciertas vertientes del pasado artístico que se da en la inmediata post-dictadura, implicaron también algunos recortes de otros aspectos de ese pasado. De hecho, de las investigaciones que indagan en las experiencias de la pre-dictadura que hemos referenciado (Verzero, 2013; Longoni, 2014; Mercado 2018) se deriva que dichas propuestas no sólo se conformaron como plataformas de acción contra la dictadura sino también como experimentos de nuevas maneras de hacer colectivo. En este sentido, resulta sugerente pensar los modos en los que diversas experiencias arte-transformadores contemporáneas actualizan y resignifican las propuestas artístico-políticas pre-dictatoriales recuperando otros aspectos de aquellas experiencias que no necesariamente se reducen al llamado a la concientización política revolucionaria. ${ }^{10}$ En efecto, uno de estos ejes en torno a ampliar las

9 El Parakultural suele también ser referencia ineludible de este tipo de propuestas experimentales en la inmediata post-dictadura. Un sótano convertido en espacio cultural que conjugaba noches de teatro, música en vivo, artes plásticas que suele ser evaluado como referencia obligada del teatro "under" de los años 80 (Infantino, 2014). 10 Un caso ejemplificador en esta línea es la recuperación que se realiza desde el actual Teatro Comunitario de ciertas experiencias colectivas y experimentales que se desarrollaron en el país en tiempos pre-dictatoriales, como las propuestas de Teatro del Oprimido desarrolladas por el dramaturgo y director brasileño Augusto Boal. Si bien diversos grupos se distancian de cierta lectura maniqueísta de la relación opresores/oprimidos de las primeras producciones de Boal, hay por otro lado recuperaciones/actualizaciones de algunas de sus conceptualizaciones como por ejemplo la propuesta de poner el lenguaje teatral a disposición de cualquier sujeto, no necesariamente un actor profesional. Un análisis acerca de estas resignificaciones y los modos en que las nuevas generaciones actualizan esos métodos en propuestas colectivas de acción puede verse en Mercado, 2018. 
potencialidades críticas del arte se vincula con la ocupación del espacio público con propuestas que no necesariamente debían tener "un mensaje" político. Comparto una cita de una artista circense callejera para dar cuenta de estos debates:

quizás en la calle no siempre contás algo comprometido. Hay gente que baja mucha línea [en referencia a un mensaje o línea político-ideológica] en sus espectáculos y otra que no tanto pero para mí ya estar trabajando en la calle es bajar línea aunque no estés diciendo nada. La elección de pasar la gorra [modalidad de cobro del espectáculo a través del aporte voluntario de los espectadores] y de trabajar en la calle ya es una línea ideológica, es popular, es una forma de pensar el arte. (Entrevista a artista circense, 2008)

Esa "forma de pensar el arte" vinculada al espacio callejero implicó un cuestionamiento a las dinámicas de legitimación hegemónica en el campo del arte así como a sus espacios consagrados de exhibición y circulación. La disputa por otras formas de hacer arte -más popular, comprometido, transgresor, crítico- se vinculó con la ampliación y pluralización de las políticas culturales que mencionaba en la introducción de este trabajo. Transcender una visión elitista y restringida de la cultura fue un ámbito para cuestionar los espacios de circulación del arte, el acceso al consumo artístico y su potencial democratización.

Muchos de estos artistas desde esas búsquedas iniciales de los años 80 comenzaron a pensar en nuevas formas de intervenir política y socialmente desde el arte en un contexto de crecimiento de políticas de corte neoliberal como los años 90 . Mientras emergieron propuestas "novedosas" que suelen ser analizadas en términos de arte político o activismo artístico, ${ }^{11} \mathrm{mu}-$ chos colectivos de artistas que durante los años de inmediata post dictadura habían desplegado su arte en el espacio público, comenzaron a accionar también desde otras aristas. La noción de "llevar el arte a las calles" con la intencionalidad de democratizar el acceso se complementó con la noción del derecho a la experiencia y protagonismo de todos en el arte.

Desde propuestas artístico-educativas fuertemente influenciadas por pedagogías críticas, educación popular y estrategias de producción artísticas colectivas y participativas, se multiplicaron desde mediados de los años 90 experiencias que tienen en común, entre otras cosas, defender el derecho a la experiencia artística colectiva. Así, cuestionan la representación hegemónica que adjudica la capacidad creativa artística solo a algunos pocos elegidos; actúan desde estrategias colectivas-participativas de producción de obras; suelen asentarse en territorios específicos articulando con demandas de las propias comunidades; se juntan en redes que potencian el trabajo colectivo y las estrategias para sostener y reproducir sus prácticas; se apropian del arte como instrumento/recurso para intervenir y transformar diversos aspectos: individuales, comunitarios, sociales.

Si pensamos junto a Richard (2011) que "lo político y lo crítico en el arte" se definen en acto y en situación, o sea, son contextuales y coyunturales, podemos entonces pensar que dicha politicidad no será la misma en distintos contextos tanto territoriales como de época.

Los horizontes de lo crítico y lo político dependen de la contingente trama de relacionalidades en la que se ubica la obra [o la práctica artística] para mover ciertas fronteras de restricción o control, presionar contra ciertos marcos de vigilancia, hacer estallar ciertos sistemas de prescripciones e imposiciones, descentrar los

11 Por ejemplo, el Grupo de Arte Callejero (GAC) o el Grupo Etcétera podrían enmarcarse en estas tendencias. Ambos colectivos colaboraron con la agrupación H.I.J.O.S (Hijos por la Identidad y la Justicia con el Olvido y el Silencio), que nuclea a los hijos de desaparecidos y exiliados políticos de la última dictadura militar argentina, en el desarrollo de estrategias -artístico/performáticas- de denuncia a los militares genocidas (Longoni, 2010; Krochmalny, 2012). 
lugares comunes de lo oficialmente consensuado. (Richard, 2011, s/p)

Las experiencias que en Argentina comenzaron a desarrollarse en la post dictadura se identificaron con otras modalidades de pensar las potencialidades políticas del arte, criticando su reducción a los contenidos/temáticas de la obra en pos de concientizar al pueblo, y buscando nuevos espacios y ejes para intervenir políticamente. Tal como argumentaba anteriormente, esta crítica no necesariamente implicó una ruptura radical con el pasado. De hecho, los vínculos entre prácticas artísticas críticas post-dictatoriales y experiencias colaborativas y vanguardistas previas a la dictadura pueden rastrearse en diversos ejes -cruces de lenguajes o liminalidad disciplinaria, en términos de Verzero (2013), creación colectiva, experimentación-, aun cuando estas genealogías no sean del todo visibles en la actualidad. Así, en este proceso de expansión de los horizontes de lo crítico en el arte, emergieron la ocupación del espacio público como ámbito desde el que cuestionar los espacios hegemónicos de circulación del arte, la inauguración de experiencias de enseñanza y creación colectiva que disputen los sujetos legitimados para la producción artística y el trabajo desde la potencia creativa/colectiva para denunciar, criticar y pensar modos alternativos de ordenamiento del mundo. Si bien esta ampliación implicó ciertas potencialidades para estas experiencias, también conllevó dilemas, principalmente en torno a la tensión entre utilizar el arte como un medio para intervenir/transformar/incluir/ampliar derechos y los requisitos de medir los resultados de dichas intervenciones o su "impacto" social.

b) Del "impacto social" de las artes a la experiencia artística como derecho

Nosotros hacemos arte. No sólo brindamos acceso a la cultura en sectores vulnerados, más bien brindamos derecho a la creación entre los jóvenes. Cuando vamos a una villa en Buenos Aires, Brasil, Chile, Colombia o Perú, miramos potencia creativa y no carencias (Junior Perin, Charla Circo Social en el $5^{\circ}$ Festival Internacional de Circo Buenos Aires. Polo Circo, mayo 2013)

Nosotros tenemos desde siempre este conflicto de que cuando apelamos a espacios que tienen que ver con lo cultural artístico nos dicen que nosotros somos un proyecto social y cuando apelamos a espacios que tienen que ver con el desarrollo social nos dicen que somos un proyecto cultural artístico, no encontramos nunca un lugar para que se entienda que somos las dos cosas. (Entrevista a directoras de fundación ph15, 2015, en: Moyano, 2017: 52) ${ }^{12}$

Hoy pondría el foco en que es un acto revolucionario agrupar a la gente y darle un sentido de pertenencia. (...) El Teatro Comunitario quizás lo que permite es que aparezcan las herramientas, dispara. Pero no baja una fórmula de transformación social. Puede ser una transformación individual que mueva a transformaciones sociales. Una sale empoderada, sale más sensibilizada. Y esto lo pienso también en relación a haber trabajado con pibes en situación de peligro ¿no? Pibes recuperándose de adicciones. Y pienso: - ¿Le cambia la vida que yo le enseñe a actuar?-. El pibe no va a ser actor y así se va a ganar la vida ¿entendés? (Entrevista a Gilda Arteta, referente del Grupo de Teatro Comunitario Catalinas Sur, 2015. En: Mercado, 2018:177) ${ }^{13}$

El discurso de la 'salvación a través del arte', especialmente para la población pobre, los 'carentes' y dentro de ella a las y los jóvenes, 'los riesgosos', debería ser analizado con especial atención por todos los que, desde diferentes perspectivas, formamos parte de este tipo de iniciativas sociales y sus redes; ya que, de lo contrario, se corre el riesgo de mistificar su potencial y reducir su contenido a meros instrumentos, en vez de resaltar como su principal atributo el de orientarse por la lógica del acceso y disfrute de experiencias artísticas enriquecedoras, inspiradas en la efectiva vigencia y ampliación de los derechos de ciudadanía. (Roitter, 2009: 3)

12 La narrativa compartida proviene de la investigación realizada por Mariana Moyano con la Fundación ph15, colectivo de artistas que trabajan a partir de la fotografía con niños, niñas y jóvenes de Ciudad Oculta -barrio segregado de la ciudad de Buenos Aires-. Para profundizar sobre el caso ver: Moyano, 2017.

13 En este caso, la narrativa citada proviene del trabajo realizado por Camila Mercado con los dos grupos pioneros de Teatro Comunitario de la Ciudad de Buenos Aires: Catalinas Sur y El Circuito Cultura Barracas. Para profundizar ver: Mercado, 2018. 
En charlas, debates y foros en los que se encuentran artistas, gestores, educadores y trabajadores culturales se suelen escuchar algunas reflexiones en torno a la problemática de la medición de los "impactos" sociales del arte y su potencial transformador. Los artistas suelen plantear que si bien las experiencias colectivas de formación y creación artística que desarrollan transforman realidades, disputan inequidades y permiten imaginar y luchar por alternativas de ordenamientos sociales menos injustos y desiguales, frecuentemente el requisito de evidenciar su "utilidad" o su "impacto" se convierte en un dilema.

Las citas que compartí como epígrafes nos colocan ante esa tensión. Nosotros luchamos por el "derecho a la creación" entre jóvenes vulnerados haciendo arte, en palabras de un referente de Circo social en Brasil; nosotros peleamos por que se comprenda que "somos las dos cosas", tanto un proyecto social como uno cultural-artístico, en las voz de la fundación ph15 que trabaja desde la fotografía junto a jóvenes en barrios segregados de la ciudad de Buenos Aires; el Teatro comunitario puede ser pensado como un "acto revolucionario" en tanto agrupa a la gente y le da un "sentido de pertenencia", en palabras de una referente del grupo pionero de este tipo de Teatro en la ciudad de Buenos Aires, pero no le "cambia la vida" a un joven que atraviesa situaciones de peligro. Las palabras de Roitter alertan acerca del riesgo de actuar desde el arte como estrategia de "salvación" para los "carentes" y/o "riesgosos". Las citas justamente evidencian esta tensión en relación con qué, cómo, de qué manera y cuánto transforma el arte: ¿Salva? ¿Cambia vidas? ¿Es un derecho? ¿Es social o artístico?

Considero que estos debates y tensiones se vinculan estrechamente con cuestiones de poder que se entrelazan con cuestiones económicas. Las propuestas, acciones y políticas de intervención social desde el arte suelen ser financiadas tanto por dinero público -estados nacionales, provinciales y/o municipales a través de subsidios y/o de programas de política pública- como por la cooperación internacional. Si bien la diversidad de formas de gestión del campo arte-transformador incluye experiencias gestadas desde organizaciones de la sociedad civil -tanto formales como informales- y propuestas estatales, tanto unas como otras atraviesan los dilemas de tener que mostrar sus resultados en términos de impacto.

En el contexto argentino, los años 90 en que se instalaron y crecieron las propuestas arte-transformadoras fueron los años de políticas focalizadas, de representaciones estigmatizantes acerca de las poblaciones subalternas, de responsabilización de la pobreza en los individuos que, a través de diversas propuestas entre las que se destacaban las artísticas/culturales, debían modificar individualmente sus condiciones de vulnerabilidad. En este sentido, no es casual que en ese contexto muchas de las propuestas arte- transformadoras hayan tenido que justificar sus acciones en un paradigma preventivo/asistencial que postulaba el arte como un instrumento para ayudar, asistir, salvar, incluir (Kantor, 2008; Roitter, 2009) y/o gestionar el "riesgo social" (Murillo, 2006), adjudicado a los carentes, los pobres, los excluidos.

Analicé particularmente en otros trabajos (Infantino, 2016, 2018a, 2019b) cómo el paradigma asistencial/preventivo en las artes se convirtió en discurso hegemónico en los años 1990, aun cuando el paradigma de derechos también se erigía como otro espacio de sustento. No obstante, a partir del nuevo milenio en el ámbito de la cultura en Latinoamérica comenzó a instalarse un viraje. Aquí, los conceptos de derechos culturales y democracia cultural participativa (Chauí, 2013; Calabré y Rebello, 2014; Vich, 2014) así como una conceptualización ampliada y diversa de lo cultural/artístico se fue asentando con mayor fuerza que en contextos precedentes. 
Más allá de la implementación efectiva o no de esta conceptualización de políticas culturales y el entrecruzamiento con tendencias en las que la visión utilitaria e instrumental de la cultura continuó primando, lo cierto es que este contexto regional instaló un fuerte discurso de reivindicación del rol del Estado como garante de derechos, entre ellos los derechos culturales. Asimismo, movilizó a diversos colectivos artísticos hacia demandas por políticas culturales participativas e inclusivas, movilizaciones que en cierta manera estuvieron en la base de los nuevos modelos de políticas culturales. De esta manera, la apelación a la cultura como derecho implicó ciertos espacios para disputar esos usos meramente instrumentales/utilitarios que recorríamos anteriormente. No obstante, las maneras que este cuestionamiento fue adquiriendo no liberaron a los hacedores culturales de la necesidad de medir/demostrar los impactos de lo que realizan.

Cabe destacar que la creciente institucionalización de las propuestas arte-transformadoras conlleva procesos de profesionalización en los que artistas, educadores y trabajadores culturales deben cada vez más responder al requisito de medición y rendición de cuentas que en cierta medida traen aparejados la estandarización de las propuestas y sus potencialidades. En este sentido, resulta central articular un análisis crítico que dé cuenta tanto del potencial transformador de estas prácticas como de las relaciones de poder desiguales que las atraviesan. Propongo entonces recorrer algunas estrategias que, no sin complejidades, han permitido a los hacedores del campo arte-transformador resignificar los impactos/potencialidades del arte. Considero que estas estrategias pueden brindar algunas referencias para pensar intersticios desde los cuales potenciar miradas críticas/democratizantes que trasciendan los usos instrumentales de las artes.

\section{LAS POTENCIALIDADES DEL ARTE: LA COLECTIVIDAD Y LA DISPUTA POLÍTICA}

[El arte] puede contribuir a transformar el mapa de lo perceptible y de lo pensable, a crear nuevas formas de experiencia de lo sensible, nuevas distancias con las configuraciones existentes de lo dado. (Rancière, 2013: 69)

Las prácticas artísticas y culturales pueden ofrecer espacios de resistencia que socaven el imaginario social necesario para la reproducción capitalista. [...] Es aquí donde reside el gran poder del arte: en su capacidad para hacernos ver las cosas de una manera diferente y para hacernos percibir nuevas posibilidades. (Mouffe, 2014: 95, 103).

En líneas generales, podríamos argumentar junto a los autores citados que las potencialidades crítico-políticas del arte estarían enmarcadas en potenciar nuevas alternativas. En esta tendencia también se inscriben las propuestas recientes acerca de cómo pensar políticas culturales "más políticas", en términos de Vich, en tanto deberían "servir para revelar como las normas culturales que nos han socializado corresponden a patrones de poder, pero sobre todo, para deconstruirlas, deslegitimarlas y para comenzar a construir otras nuevas" (Vich, 2014: 38). Algunas de las líneas desde las cuales se han ampliado las connotaciones de estas potencialidades en las experiencias arte-transformadoras nos dirigen a este ámbito de reflexiones.

a) Los cuestionamientos ante la autonomía del campo y la restricción/elitización del arte y el artista habilitaron otras maneras de concebir la diversidad artístico-cultural. Así han llevado a potenciar la disputa ante las jerarquías artísticas y a favorecer la emergencia de nuevos estilos artísticos, nuevos circuitos de circulación y nuevas ofertas culturales, pedagógicas y de intervención social. 
Podríamos pensar en múltiples ejemplos. Algunas propuestas acentúan las corporalidades y otras maneras de vincularse con los propios cuerpos y los de otros en el hacer colectivo -circo, danza-; otras demuestran que a través de las imágenes -murales, fotografía, artes visuales- se pueden cuestionar representaciones estigmatizantes acerca de las poblaciones subalternizadas; algunas proponen nuevas modalidades de comunicación popular -radios y medios gráficos y audiovisuales alternativos- que disputen los discursos de los medios hegemónicos; otras promueven nuevas y/o resignificadas sonoridades y modalidades de producción musical que entrelazan músicas académicas con diversos estilos otrora deslegitimados; otras promueven formas colectivas de producción teatral que articulan tradiciones populares locales con temáticas frecuentemente acalladas por las historias oficiales -Teatro comunitario-. Sin embargo, muchas de estas propuestas se entrecruzan, trabajan en redes, se potencian en la acción colectiva y en el cruce de lenguajes, generando nuevos estilos y nuevas propuestas educativas y de intervención.

Tal como lo señalaban desde una de estas redes colectivas, ${ }^{14}$ este tipo de propuestas pueden ser entendidas como la tarea sostenida que desarrollan infinidad de ciudadanos y ciudadanas con distintos niveles de formalización institucional destinadas a fomentar:

un modo particular de acción en el territorio y en el espacio público, con un específico modo de producción de obras y contenidos que no encuentran su sentido final en los circuitos y las jerarquizaciones instituidas en cada disciplina o lenguaje artístico o comunicacional trabajado, sino que se articulan en procesos comunitarios y colectivos cuyo objeto final es la transformación misma del espacio compartido y de las visiones de los actores interpelados, en una experiencia integral en el territorio. (Pueblo Hace Cultura, 2012: 3)

Ahora bien, estas potencialidades no se amoldan fácilmente a los indicadores de "impacto" medibles, tangibles, cuantificables que se le demandaron y aun se le demandan a las propuestas arte-transformadoras. Hace diez años Roitter (2009) señalaba estos desafíos en función de concebir un nuevo lenguaje para discutir sobre impactos artísticos. Considero que las propias experiencias arte-transformadoras y la emergencia de un campo de estudios-académicos y no académicos- alrededor de las mismas vienen dando respuesta ante estos desafíos. Las "prácticas intelectuales" 15 que involucran cada vez mayores grados de sistematización y reflexión crítica alrededor de este tipo de experiencias, no solo están brindando datos/resultados sino también aportes para cuestionar las tendencias que rodearon el requisito de la medición.

La "intangibilidad" de los procesos/experiencias artísticas y sus resultados en el largo plazo se evidencian en propuestas arte-transformadoras que ya llevan dos o tres décadas de trabajo ininterrumpido. Muchas de estas organizaciones y experiencias a través de su continuidad en el

14 Pueblo Hace Cultura: "Colectivo de organizaciones sociales, culturales, medios de comunicación populares, fuerzas políticas por una Ley de Apoyo a la Cultura Comunitaria”. Información disponible en: https://www.facebook.com/pueblohacecultura/info/?tab=page_info

15 Retomo el concepto de la propuesta de Daniel Mato (2002) y Mario Roitter (2009) que aporta críticas epistemológicas y ontológicas a la posición dominante de unas formas de saber -objetivo, racional, positivista, realizado por "los que saben", o sea los académicos- sobre otras -subjetivo, basado en la práctica, no sistematizado/ caótico, realizado por "los que hacen"-. Los autores proponen por un lado cuestionar las jerarquizaciones que no reconocen los saberes producidos por "los que hacen" y reconocer que, frecuentemente, la generación, circulación y distribución de conocimiento "se legitima si y sólo si es producida por investigadores que realizan su trabajo dentro de las fronteras de la academia" (Roitter 2009:5). Roitter así propone entrecruzar estos dos tipos de prácticas intelectuales, generando articulaciones. Considero que gran parte de la producción en el campo arte transformador de los últimos años en el país y en la región viene aportando en estos cruces: artistas que también son académicos o viceversa; equipos y proyectos de investigación conformados por artistas y académicos; enlaces de proyectos arte-transformadores con universidades públicas; trabajos colaborativos en el diseño de políticas culturales; entre otros. 
hacer colectivo, demuestran que esas prácticas producen transformaciones. Y que dichas transformaciones no pueden ser valoradas solo en términos cuantificables, al estilo, cuántos jóvenes asistieron o mejoraron su inserción académica y/o laboral. Más bien deben ser evaluadas por otras nociones de calidad/impacto en las que el cómo y el derecho a la experiencia artística se pondera por sobre el resultado/producto.

Esto no quiere decir que la noción de calidad artística no intervenga, más bien se cuestiona una restricción del criterio de calidad limitado a una noción universalista-normativa de arte: la que prevaleció en la jerarquización de las bellas artes por sobre otras modalidades de expresión humana; y en el producto, la obra de arte. Las propuestas arte-transformadoras evidencian que la experiencia artística, en el proceso colectivo del hacer obra, en el acontecimiento -también colectivo- de la puesta en acto o en la transmisión de saberes, expande sus potencialidades a todos estos ámbitos.

En este sentido, distinguir que lo que se puede impactar/transformar desde el arte va más allá de la obra/producto artístico así como de sus potenciales impactos -mejora en el desarrollo económico o social de los vulnerados- implica también situarse en la potencialidad de la inminencia del arte en tanto su capacidad para anunciar algo que puede suceder de otras maneras (García Canclini, 2010). La experiencia de percibir en lo que es las otras posibilidades de ser, nos dirige hacia otras formas de concebir las potencialidades críticas/transformadoras/políticas del arte. La disputa por el derecho a la experiencia artística coloca a lo político del arte en otro registro: el arte ya no debería justificarse porque ayuda, salva o emancipa/concientiza sino más bien porque permite pensar e imaginar alternativas al actual ordenamiento del mundo y luchar colectivamente por lograrlas.

Ahora bien, la emergencia y potencia de estas propuestas que en función de su permanencia y continuidad han generado nuevas posibilidades -colectivas, cuestionadoras, críticas- para la producción y reproducción artística/cultural, no puede ser vista como un proceso sin conflicto. La diversidad/diferencia se entrecruza con la desigualdad y el poder. Coincido con Vich cuando argumenta que "no se pueden construir políticas culturales basadas en una opción por la diferencia sin cuestionar, al mismo tiempo las relaciones sociales por las cuales esta aparece subalternizada y queda inscripta en relaciones de dominación y poder" (Vich, 2014: 35).

En definitiva, las propuestas arte-transformadoras que cuestionan los usos instrumentales de las artes y sus posibles "impactos" no pueden ser escindidas de las relaciones de poder desiguales que intervienen en la valoración, discusión y visibilización de dichas propuestas. Considero entonces que las estrategias desplegadas por colectivos artísticos en pos de demandar reconocimiento tanto material como simbólico al Estado que se vienen dando en el campo de la cultura en años recientes, resulta también un eje para dar cuenta de esas relaciones desiguales de poder y de los intersticios que se vienen ocupando para disputarlas.

b) Disputar colectivamente reconocimiento y recursos para el despliegue de prácticas artísticas transformadoras

Tal como citaba en uno de los epígrafes del apartado anterior, generar espacios colectivos, de pertenencia, de socialización y de producción colectiva de arte en un mundo individualista como el que habitamos, ya de por sí podría ser considerado "un acto revolucionario". Sin idealizar estos procesos, considero que más allá de las potencialidades intrínsecas de democratización 
del derecho al arte y los posibles impactos -subjetivos, estéticos, comunitarios y sociales- que acarrean estas propuestas, debemos también considerar las potencialidades de los movimientos reivindicativos de derechos culturales para este tipo de experiencias que se fueron sucediendo en Latinoamérica y en Argentina en años recientes.

En el apartado anterior mencioné la emergencia de una nueva manera de concebir las políticas culturales en el nuevo milenio. La experiencia de Brasil, ${ }^{16}$ su extensión a Latinoamérica y el modo en que se fue instalando un viraje en materia de políticas culturales habilitaron espacios para disputar el requisito de "impacto" para el desarrollo social y económico y la postulación del arte y la cultura como derecho. En efecto, la noción de "cultura viva" plasmó en una política pública el desplazamiento de sentido en torno a la noción de cultura y arte que venía desplegándose desde coyunturas anteriores: la expansión de la idea de artista, productor/hacedor cultural a agentes que otrora no habían sido considerados como tales (Turino, 2013).

Si bien la instrumentalización del arte y la cultura para el desarrollo económico y social y los requisitos de mediciones no desaparecieron, lo que si sucedió fue una ampliación de posibilidades desde las que se pudo pensar el rol del arte/cultura, los artistas y el Estado.

Es aquí donde argumento que este viraje no puede ser pensado sin atender a las movilizaciones colectivas que implicaron que esas demandas por reconocimiento material y simbólico, trascienden los casos individuales y se potencien. Particularmente en Argentina, la última década ha sido escenario de demandas protagonizadas por diversos colectivos artísticos en función de lograr visibilidad, espacio, reconocimiento y recursos para el desarrollo de sus prácticas. Hacedores y trabajadores culturales referentes de distintos lenguajes -músicos, cirqueros, bailarines, actores, artistas callejeros, artistas comunitarios- han demandado y/o continúan reclamando instrumentos -leyes de promoción, creación de programas de política pública, declaratorias patrimoniales, etc.- que contemplen las particularidades de sus prácticas artísticas y sus necesidades en pos de garantizar la producción y reproducción de las mismas.

Lo interesante en estos procesos es justamente el modo en que los propios hacedores culturales trascienden sus disputas internas como estrategia colectiva de fortalecimiento político. En los estudios sobre prácticas artístico-culturales solemos pensar en las disputas y los consensos casi como categorías teóricas contrapuestas, dicotómicas, al interior de campos o mundos de arte, retomando las nociones de Bourdieu y Becker respectivamente (1995; 2008). Tal como sugiere Cingolani (2019) considero que, más que hablar de disputas y consensos como dos modos de vinculación antagónicos y distantes entre los actores, es preciso pensar en vínculos circunstanciales, móviles y cambiantes.

En efecto, a lo largo de mis años de trabajo con la formación cultural circense relevé intensas disputas en torno a la definición de las maneras legítimas de hacer circo que, principalmente,

16 La importancia de las políticas culturales desplegadas por Brasil en estos años bajo el Ministerio de Gilberto Gil en la primera presidencia de Lula da Silva (2003-2008) y su impacto regional amerita un desarrollo específico que por espacio no puedo desarrollar aquí. No obstante, señalo que la importancia de ciertos movimientos regionales - por ejemplo, Plataforma Cultura Puente y la demanda por que los Estados nacionales garanticen un 0,1\% de sus presupuestos para promover y favorecer el desarrollo de la "cultura viva comunitaria"- se vincula a su vez a la conformación previa de redes nacionales y regionales que fueron instalando las nociones de arte y transformación social así como las demandas por legislación y políticas públicas en distintos países Latinoamericanos. Para profundizar en este tema ver: Turino, 2013; Calabré y Rebello, 2014; Santini, 2017; Infantino, 2019b. 
se traducían en dicotomías como popular/ refinado, contemporáneo/ tradicional, comprometido-politizado/ mercantilizado-elitizado. Estudié cómo estas divergencias ponían de relieve posturas artísticas, estéticas, políticas e ideológicas diferenciales, así como disputas por recursos tanto económicos como simbólicos (Infantino, 2014). Ahora bien, cuando los y las artistas circenses se organizaron colectivamente para demandar por una ley nacional de Circo, si bien estas disputas no se diluyeron, el énfasis se colocó "en trascenderlas apelando a un sentido colectivo, de comunidad, que incorpore las diversidades de estilos, historias, procedencias, trayectorias en una construcción de identidad común" (Infantino, 2019c: 292) y en un reclamo político que redunde en posibles beneficios para todos los artistas circenses.

Menciono el caso de los artistas circenses, pero podemos encontrar semejanzas en los músicos independientes demandando la Ley Nacional de Música o en los bailarines haciendo lo propio con la Ley Nacional de danza, o los tangueros, murgueros, artistas callejeros, entre muchos otros. Es más, la potencia de la colectividad en el sentido de actuar juntos para enfrentar desafíos y pensar nuevas alternativas, implicó consensos y articulaciones en diversas formaciones culturales o mundos del arte, pero además se gestaron articulaciones transversales. $\mathrm{Y}$ así emergen redes internacionales como la Red Latinoamericana de Arte y Transformación social, Plataforma Puente Cultura Viva Comunitaria, o colectivos nacionales como Pueblo hace cultura, Movimiento por la Ley Federal de las culturas, entre muchos otros.

Si bien podríamos detenernos en particularidades de cada uno de los ejemplos mencionados, los retomo aquí para evidenciar procesos de politización de la cultura en tanto escenario de diputa política colectiva (Wright, 2004). Por un lado, la discursiva del arte y la cultura como herramientas asistencialistas, preventivas y/o mágicas para favorecer la inclusión, el desarrollo y/o la transformación social que caracterizó a las propuestas arte-transformadoras desde los años 90, no puede ser vista sin contemplar los mecanismos de construcción hegemónica que favoreció mucha de la cooperación internacional y su influencia en los Estados basada en concepciones de políticas focalizadas y de soluciones que responsabilizaron a los sujetos por sus situaciones de vulnerabilidad. Así, la organización de muchos de los colectivos culturales desde los años 2000 para demandar reconocimiento simbólico y material ante los Estados en un contexto más favorable a una discursiva de ampliación de derechos ciudadanos, puede ser analizada como una estrategia para disputar los requisitos de medición de "impactos" basados en los criterios antedichos.

Por otro lado, también se presentó como una estrategia para garantizar la producción y reproducción de las propuestas arte-transformadoras a largo plazo y no por proyectos que evidencien "impactos" singulares (Moyano, 2017; Mercado, 2018; Infantino, 2019b). En estas búsquedas, las redes colectivas implicaron ámbitos de articulación y socialización de saberes. La estrategia de multiplicación de enlaces territoriales (articulaciones con movimientos sociales, centros comunitarios, comedores asentados en los territorios) y de fuentes de financiación (acuerdos con agencias y fundaciones internacionales, con dependencias estatales de diferentes niveles y de distintas áreas -cultura, salud, educación, trabajo, desarrollo social-) así como la búsqueda de ingresos "genuinos" a través de la oferta de servicios culturales (espectáculos, venta de obras, entre otras) se articuló con las demandas hacia los Estados por reconocimiento y recursos. Considero que en estas búsquedas por lograr perdurabilidad de las propuestas pueden comprenderse también estas demandas hacia el Estado por recursos garantizados a través de políticas culturales que aseguren la promoción de este tipo de propuestas en tanto derechos. $\mathrm{Y}$, de manera paralela, este tipo de disputas conlleva el cuestionamiento a las mediciones de 
“impacto" como elemento exclusivo para justificar la existencia de las propuestas arte transformadoras.

\section{REFLEXIONES FINALES}

A lo largo de este trabajo desarrollé un análisis que pretendió evidenciar cuanto de contextual tienen los "usos sociales y políticos del arte". Los sentidos con los que se connota el potencial transformador, crítico/político del arte no son unívocos y emergen de coyunturas diferenciales así como de intereses político-ideológicos específicos.

Un eje central de mi propuesta fue evidenciar que estos usos de las artes -coyunturales, contextuales- no se suceden o suplantan unos a otros. Más bien nos encontramos con superposiciones y con intersticios más o menos propicios para instalar ciertos sentidos críticos. Analicé como la expansión de la noción de transformación social desde el arte hacia concepciones que instalaron al arte como derecho más que como solución a problemáticas sociales y/o económicas encontró ciertos espacios favorables en años recientes a partir de cambios en las conceptualizaciones de las políticas culturales aunados a procesos de politización cultural (Wright, 2004).

Estos procesos en los que las propias prácticas culturales y artísticas se transforman en un espacio de disputa política me llevaron a analizar el modo en que los agentes culturales fueron instalando formas alternativas de considerar el potencial transformador de las artes. Del acento en el mensaje al foco en el resultado/impacto social y a las maneras de cuestionar dichas reducciones, analicé un proceso de disputa político-cultural que intentó y continua intentando ampliar, resignificar y expandir las potencialidades crítico-políticas del arte-transformador.

\section{BiBLIOGRAFÍA}

Bayardo, Rubens. 2008. "Políticas culturales: derroteros y perspectivas contemporâneas". RIPS. Revista de Investigaciones Politicas y Sociológicas, 7(1): 17-29.

Becker, Howard .2008. Los mundos del arte. Sociología del trabajo artístico. Buenos Aires: Universidad Nacional de Quilmes.

Belfiore, Eleonor. 2002. "Art as a mean of alleviating social exclusión: Does it really work? A critique of instrumental cultural policies and social impact studies in the UK". International Journal of Cultural Policy, 8(11): 91-106.

Bourdieu, Pierre. 1995. Las reglas del arte: génesis y estructura del campo literario. Barcelona: Anagrama.

Calabre, Lia y Rebello Lima, Deborah. 2014. "Do Do-in antropológico a política de base comunitária - 10 anos do programa Cultura Viva: Uma trajetória da relação entre estado e sociedade". Politicas Culturais em Revista, 2(7): 6-25.

Chauí, Marilena. 2013. Ciudadanía Cultural. El derecho a la cultura. Caseros: RGC Libros.

Cingolani, Josefina. 2019. Pensó que el rocanrol solo era el show. Consensos, tensiones y disputas en la configuración del circuito de rock platense. Tesis doctoral en Ciencias Sociales. La Plata: Universidad Nacional de La Plata. 
Crespo, Carolina, Morel, Hernán y Ondelj, Margarita. (comp.). 2015. “Introducción”. Pp. 5-15 en La politica cultural en debate. Diversidad, performance y patrimonio cultural. Buenos Aires: Ciccus.

García Canclini, Néstor. 1987. Políticas Culturales en América Latina. México: Grijalbo. 2010. La sociedad sin relato. Madrid: Ed. Katz.

Infantino, Julieta. 2014. Circo en Buenos Aires. Cultura, Jóvenes y Politicas en disputa. Buenos Aires: Instituto Nacional del Teatro.

. 2016. "Experiencias de intervención social desde el arte (circense) como esfera de desarrollo de políticas culturales en Argentina”. Pp. 277-311 en Dinámicas de poder, estado y sociedad civil en los procesos patrimoniales y las politicas y gestión de la cultura editado por M. Rotman. Buenos Aires: Editorial de la Facultad de Filosofía y Letras- Universidad de Buenos Aires.

. 2018a. "De pluralizar las políticas culturales al arte para la transformación social". Pp. 143-181 en Cultura, antropología y transformación social desde las políticas culturales de México, Brasil y Argentina editado por L. Cardini y D. Madrigal González. San Luis Potosí, México: E1 Colegio de San Luis.

2018b. "Working with circus artists. Reflections on a process of collaborative research, participation and commitment." Conjunctions. Transdisciplinary Journal of Cultural Participation 5(1), 1-18. doi: https://doi.org/10.7146/tjcp.v5i1.105287 . (comp). 2019a. Disputar la cultura: Arte y transformación social en la Ciudad de Buenos Aires. Caseros: RGC Libros.

. 2019b. "Políticas culturales, arte y transformación social. Recorridos, usos y sentidos diversos en espacios de disputa.” Pp. 19-64 en Disputar la cultura: Arte y transformación social en la Ciudad de Buenos Aires editado por J. Infantino. Caseros: RGC Libros.

.2019c. "Transformar, resistir, demandar. Disputas político-culturales hacia una ley nacional de circo.” Pp. 273-310 en Disputar la cultura: Arte y transformación social en la Ciudad de Buenos Aires editado por J. Infantino. Caseros: RGC Libros.

Kantor, Débora. 2008. "El mandato de la prevención en discusión”. Pp. 83-106 en: Variaciones para educar adolescentes y jóvenes. Buenos Aires: Del Estante Editorial.

Krochmanly, P. (2012). De la utopia al mercado. Los artistas de la postcrisis (Buenos Aires 20012011). (Tesis de doctorado en Ciencias Sociales). Buenos Aires: Facultad de Ciencias Sociales, Universidad de Buenos Aires.

Longoni, Ana. 2010. “(Con)textos para el GAC”. En: GAC. Pensamientos, prácticas y acciones. Pp. 9-16. Buenos Aires: Tinta Limón.

. 2014. "El mito de Tucumán Arde". École des Hautes Études en Sciences Sociales, Artelogie, 6:1-10. URI: http://hdl.handle.net/11336/35586

Mato, Daniel. 2002. Estudios y otras prácticas intelectuales latinoamericanas sobre cultura y poder. Caracas: CLACSO. Recuperado de: http://bibliotecavirtual.clacso.org.ar/ar/libros.

Menéndez, Eduardo. 2010. La parte negada de la cultura. Relativismo, diferencias y racismo. Rosario: Prehistoria.

Mercado, Camila. 2018. Trayectorias de Teatro Comunitario en Buenos Aires. Políticas culturales, autogestión y sentidos del arte en disputa. Tesis doctoral en Antropología. Buenos Aires: Facultad de Filosofía y Letras, U.B.A.

Mouffe, Chantal. 2014. Agonistica. Pensar el mundo políticamente. Buenos Aires: Fondo de Cultura Económica.

Moyano, Mariana. 2017. Revelar lo oculto. Estudio de una propuesta socio-artistica de expresión visual con jóvenes. (Tesis de Maestría en Antropología). Buenos Aires: IDES-IDAES, Universidad Nacional de San Martín, Argentina. 
Murillo, Susana. 2006. "Del par normal-patológico a la gestión del riesgo social. Viejos y nuevos significantes del sujeto y la cuestión social”. Pp. 11-38 en: Banco Mundial. Estado, Mercado y Sujetos en las nuevas estrategias frente a la cuestión social, Cuadernos de Trabajo 70. Editado por S. Murillo. Buenos Aires: Ediciones del Centro Cultural de la Cooperación Floreal Gorini.

Rancière, Jacques. 2013. El espectador emancipado. Buenos Aires: Manantial.

Richard, Nelly. 2011. "Lo político en el arte: arte, política e instituciones". ARCIS University, Santiago de Chile [En línea] Disponible en: https://hemi.nyu.edu/hemi/en/e-misferica-62/richard

Roitter, Mario. 2009. "Prácticas intelectuales académicas y extra-académicas sobre arte transformador: algunas certezas y ciertos dilemas." Nuevos Documentos CEDES, 66. Disponible en: http://www.cedes.org.ar/Publicaciones/Ndoc_c/66.pdf

Santini, Alexandre. 2017. Cultura Viva Comunitaria: políticas culturales en Brasil y América Latina. Caseros: RGC Libros.

Turino, Celio. 2013. Puntos de cultura: cultura viva en movimiento. Caseros: RGC Libros.

Verzero, Lorena. 2013. Teatro militante: radicalización artística y politica en los años 70. Buenos Aires: Biblos

Vich, Víctor. 2014. Desculturalizar la cultura. La gestión cultural como forma de acción política. Buenos Aires: Siglo Veintiuno.

Wright, Susan. 2004. "La politización de la 'cultura”. Pp. 128-141 en Constructores de Otredad. Una introducción a la antropología social y cultural. Compilado por M. Boivin, A. Rosato, V. Arribas. Buenos Aires: Antropofagia.

Yúdice, George. 2002. El recurso de la cultura. Usos de la cultura en la era global. Barcelona: Gedisa.

\section{Senses of the Critical, Political and Transformative Potential of THE ARTS}

In the last decades artists, cultural workers, educators, designers of public policies and intellectuals, among others, have been deploying a variety of proposals that promote social transformation through the most diverse artistic languages. Child and youth orchestras, community theatres, social circuses, dance groups or visual artists, and other experiments that work with, combine, collectivize or territorialize different artistic languages, propose to intervene in our unequal Latin American societies. Thus, they propose a resignification of the social and political role of art as a tool and strategy for social intervention and political dispute for the propagation of civil rights. In this article I propose to systematize some lines of reflection in relation to the social and political uses of art, in order to analyze historical processes, tensions and disputes that demonstrate that the meanings with which the transformative, critical and political potential of art is connoted are not univocal, and emerge from differential conjunctures as well as from specific political-ideological interests and contexts.

Keywords: arts, social transformation, cultural policies

Data recibido: 2019-08-30

Data aceptado: 2019-12-18 